\title{
Preoperative neutrophil-to-Iymphocyte ratio and tumor-related factors to predict lymph node metastasis in patients with pancreatic ductal adenocarcinoma (PDAC)
}

\author{
Lianyuan Tao ${ }^{1}$, Lingfu Zhang ${ }^{1}$, Ying Peng ${ }^{1}$, Ming Tao ${ }^{1}$, Gang Li $^{1}$, Dianrong Xiu ${ }^{1}$, \\ Chunhui Yuan ${ }^{1}$, Chaolai Ma ${ }^{1}$ and Bin Jiang ${ }^{1}$ \\ ${ }^{1}$ Department of General Surgery, Peking University Third Hospital, Beijing, China \\ Correspondence to: Dianrong Xiv, email: xiudianrong@hotmail.com
}

Keywords: pancreatic ductal adenocarcinoma; lymph node metastasis; prognosis; neutrophil-to-lymphocyte ratio

Received: May 09, $2016 \quad$ Accepted: July 19, 2016

Published: August 02, 2016

\section{ABSTRACT}

As a poor prognosis indicator in patients with pancreatic ductal adenocarcinoma (PDCA), lymph node (LN) metastasis is of great importance in treatment. Present study was performed to evaluate the predictive value of preoperative neutrophilto-lymphocyte ratio (NLR), Platelet-to-lymphocyte ratio (PLR) and possible clinical parameters on the LN metastasis in PDCA patients. A total of 159 operable patients with PDCA were enrolled in our study. The clinical utility of NLR and other clinical parameters was evaluated by receiver operating characteristic (ROC) curves. Overall survival analysis indicated that LN metastasis is an independent prognostic factor. The logistic analysis was used to determine the independent parameters associated with LN metastasis. Ideal cutoff values for predicting LN metastasis are 2.12 for NLR and 130.96 for PLR according to the ROC curve. Multivariate analyses indicate that NLR (HR 2.588; 95\% CI 1.246-5.376; $P=0.011$ ), CA125 (HR 6.348; 95\% CI 2.056-19.594; $P=0.001)$ and CA19-9 (HR 2.738; 95\% CI 1.151-6.515; $P=0.023)$ are associated significantly with LN metastasis independently. Preoperative NLR, CA125 and CA19-9 are useful biomarkers for the prediction of LN metastasis in PDCA patients.

\section{INTRODUCTION}

Pancreatic cancer (PC) is one of the most aggressive malignancies, and represents a leading cause of cancerrelated mortality $[1,2]$. Pancreatic ductal adenocarcinoma (PDCA) was the commonest histological type of PC. Most of $\mathrm{PC}$ patients were diagnosed at an advanced stage and its 5 -year survival rate is only $6 \%[1-3]$. Lymph node metastasis is an independent prognostic factor associated with PC, and it is of great significance for making reasonable therapeutic strategies and selection of suitable treatment options for individual patients [4-6].

Although controversies remains regarding neoadjuvant approaches in the treatment of PC recently, it has several potential advantages over adjuvant therapy, such as earlier delivery of systemic treatment, in vivo assessment of response, increased resectability rate in borderline resectable patients and increased marginnegative resection rate [7-9]. It is reported that patients with potentially resectable PDAC selected to undergo neoadjuvant therapy had improved survival and longer time to recurrence, especially for those with LN metastasis [8]. Therefore, neoadjuvant is necessary for some PDCA patients, and an accurate preoperative prediction of LN status is of critical significance for the selection of treatment for PDCA.

Imaging techniques, such as endoscopic ultrasonography (EUS), computed tomography (CT), and magnetic resonance imaging (MRI), are widely used in the evaluation of nodal status in PDCA patients, however, their application are limited because of their inconsistent sensitivities and specificities findings [1, 10-15]. Some novel serum markers, such as MMP7, MUC1 and MUC2, have been proposed to detect LN metastases in PDCA patients [16, 17]. However, their clinical applications are hard to achieve for their high cost and technological problems.

Since 2005, many studies have already been aware of the predictive value of the systemic inflammatory response in the outcome of patients undergoing resection 
Table 1: Univariate and multivariate analysis of clinicopathologic variables in relation to overall survival after curative operation

\begin{tabular}{|c|c|c|c|c|c|c|}
\hline \multirow{2}{*}{ Parameter } & & & Univariate analysis & & Multivariate analysis & \\
\hline & & Number & Hazard ratio( $95 \%$ CI $)$ & $P$ value & Hazard ratio( $95 \%$ CI $)$ & $P$ value \\
\hline \multirow[t]{2}{*}{ Gender } & male & 100 & & & & \\
\hline & female & 59 & $1.307(0.887-1.926)$ & 0.176 & & \\
\hline \multirow[t]{2}{*}{ Age } & $<65$ & 86 & & & & \\
\hline & $\geq 65$ & 73 & $1.730(1.167-2.567)$ & 0.006 & $1.493(1.045-2.132)$ & 0.028 \\
\hline \multirow[t]{2}{*}{$\operatorname{Albumin}(\mathrm{g} / \mathrm{dL})$} & $<3.5$ & 18 & & & & \\
\hline & $\geq 3.5$ & 141 & $1.430(0.754-2.711)$ & 0.274 & & \\
\hline \multirow[t]{2}{*}{$\mathrm{CEA}(\mathrm{ng} / \mathrm{mL})$} & $<5$ & 117 & & & & \\
\hline & $\geq 5$ & 42 & $2.696(1.608-4.518)$ & $<0.0001$ & $1.725(1.155-2.575)$ & 0.008 \\
\hline \multirow[t]{2}{*}{$\mathrm{CA} 125(\mathrm{U} / \mathrm{mL})$} & $<35$ & 128 & & & & \\
\hline & $\geq 35$ & 31 & $1.694(0.973-2.947)$ & 0.062 & & \\
\hline \multirow[t]{2}{*}{ CA19-9(U/mL) } & $<39$ & 34 & & & & \\
\hline & $\geq 39$ & 125 & $1.360(0.811-2.281)$ & 0.244 & & \\
\hline \multirow[t]{2}{*}{ PLR } & $<130.96$ & 62 & & & & \\
\hline & $\geq 130.96$ & 97 & $1.217(0.720-2.057)$ & 0.463 & & \\
\hline \multirow[t]{2}{*}{ NLR } & $<2.12$ & 53 & & & & \\
\hline & $\geq 2.12$ & 106 & $1.226(0.745-2.019)$ & 0.422 & & \\
\hline \multirow[t]{4}{*}{ ABO blood type } & A & 55 & & & & \\
\hline & $\mathrm{AB}$ & 20 & $1.499(0.779-2.884)$ & 0.226 & & \\
\hline & $\mathrm{B}$ & 50 & $0.633(0.382-1.049)$ & 0.076 & & \\
\hline & $\mathrm{O}$ & 34 & $0.992(0.597-1.647)$ & 0.975 & & \\
\hline \multirow[t]{3}{*}{ Location } & $\begin{array}{l}\text { uncinate } \\
\text { process }\end{array}$ & 52 & & & & \\
\hline & head & 71 & $1.727(1.078-2.768)$ & 0.023 & & \\
\hline & body and tail & 36 & $1.358(0.808-2.281)$ & 0.248 & & \\
\hline \multirow[t]{5}{*}{ Differentiation } & poor & 20 & & & & \\
\hline & \begin{tabular}{|ll}
$\begin{array}{l}\text { poor } \\
\text { moderate }\end{array}$ & to \\
\end{tabular} & 56 & $0.858(0.440-1.672)$ & 0.652 & & \\
\hline & moderate & 69 & $0.586(0.300-1.146)$ & 0.118 & & \\
\hline & \begin{tabular}{|ll} 
well to \\
moderate \\
\end{tabular} & 12 & $0.598(0.229-1.561)$ & 0.294 & & \\
\hline & well & 2 & $1.215(0.240-6.165)$ & 0.814 & & \\
\hline \multirow[t]{2}{*}{ Diameter $(\mathrm{cm})$} & $<3.5$ & 69 & & & & \\
\hline & $\geq 3.5$ & 90 & $1.757(1.143-2.700)$ & 0.01 & & \\
\hline \multirow[t]{4}{*}{$\mathrm{T}$} & 1 & 12 & & & & \\
\hline & 2 & 43 & $1.988(0.782-5.055)$ & 0.149 & $2.133(0.888-5.122)$ & 0.09 \\
\hline & 3 & 103 & $2.281(0.904-5.753)$ & 0.081 & $3.263(1.414-7.528)$ & 0.006 \\
\hline & 4 & 4 & 4.906(1.159-20.767) & 0.031 & $7.314(2.008-26.644)$ & 0.003 \\
\hline \multirow[t]{2}{*}{$\begin{array}{ll}\text { Lymph } & \text { node } \\
\text { status }\end{array}$} & Negative & 70 & & & & \\
\hline & Positive & 89 & $1.586(1.035-2.431)$ & 0.034 & $1.751(1.208-2.538)$ & 0.003 \\
\hline
\end{tabular}

NLR, Neutrophil-to-lymphocyte ratio; PLR, platelet-to-lymphocyte ratio 
Table 2: Comparison of quantitative clinical factors between lymph node negative group and lymph node positive group.

\begin{tabular}{|l|l|l|l|l|l|}
\hline & \multicolumn{2}{|c|}{ Lymph node-negative } & \multicolumn{2}{c|}{ Lymph node-positive } & \\
\hline Factors & Mean & $\begin{array}{l}\text { Standard } \\
\text { deviation }\end{array}$ & Mean & $\begin{array}{l}\text { Standard } \\
\text { deviation }\end{array}$ & P value \\
\hline Age(years) & 62.045 & 10.94 & 64.557 & 9.417 & 0.125 \\
\hline Albumin(g/dL) & 40.9 & 5.796 & 36.313 & 13.167 & 0.208 \\
\hline CEA(ng/mL) & 6.031 & 8.947 & 4.103 & 4.055 & 0.602 \\
\hline CA125(U/mL) & 28.841 & 29.303 & 17.528 & 20.663 & $<0.001$ \\
\hline CA19-9 $(\mathbf{U} / \mathbf{m L})$ & 558.313 & 891.257 & 212.849 & 253.049 & $<0.001$ \\
\hline Platelet $\left(\times \mathbf{1 0}^{\mathbf{3}} / \mathbf{m L}\right)$ & 210.214 & 70.329 & 203.914 & 63.546 & 0.583 \\
\hline Lymphocyte $\left(\times \mathbf{1 0}^{\mathbf{3}} \mathbf{m} \mathbf{m}\right)$ & 1.44 & 0.599 & 1.43 & 0.481 & 0.805 \\
\hline Neutrophil $(\times \mathbf{1 0} / \mathbf{m L})$ & 3.75 & 1.266 & 3.98 & 1.859 & 0.675 \\
\hline PLR & 187.001 & 89.158 & 141.856 & 68.02 & $<0.001$ \\
\hline NLR & 3.43 & 1.704 & 2.811 & 1.828 & 0.006 \\
\hline Diameter(cm) & 4.101 & 2.285 & 3.645 & 1.678 & 0.158 \\
\hline
\end{tabular}

NLR: neutrophil/lymphocyte rates; PLR: Platelet/lymphocyte rates

for pancreatic cancer [18-21]. Neutrophil, one of the most important part of WBCs in the systemic inflammatory response, have been recognized as key participator for metastasis based on increasing evidence [22-25]. Neutrophil-to-lymphocyte ratio (NLR), one of the most used clinical parameters for the evolution of neutrophils, was considered as a convenient marker for the predictor of poor prognosis for pancreatic cancer [26-28]. Whether NLR can predict the Lymph node (LN) metastasis of PDCA is still unknown. Therefore, we performed a retrospective analysis of predictor value of NLR and possible clinical parameters on the $\mathrm{LN}$ metastasis of PDCA before operation.

\section{RESULTS}

\section{Patient characteristics}

One hundred and fifty-nine patients who had undergone a primary attempt of a curative resection for PC were enrolled, including 100 males and 59 females ranging in age from 23 to 86 years, with a mean of 63.4 years. All patients' diagnoses were ultimately confirmed both clinically and pathologically and LN metastases were also confirmed pathologically. General clinical factors are summarized in Table 1 and Table 3 and quantitative clinical factors are shown in Table 1. Among the 159 patients, $89(56.0 \%)$ patients were discovered developing $\mathrm{LN}$ metastases during operation.
Comparison of the clinical variables in relationship to OS after curative operation

In the univariate analysis, greater age $(P=0.006)$, CEA $(P<0.0001)$, tumor diameter $(P=0.01)$, T stages $(P<0.05)$, and lymph node-positive $(P=0.034)$ were significant prognostic factors for OS (Table1). The NLR and PLR were not significant predictors of OS $(P>0.05$ each; Table1). Moreover, in the multivariate analysis, lymph node-positive $(P=0.034)$, together with greater age $(P=0.003)$, CEA $(P=0.008)$, and T stages $(P<0.05)$, were also a significant predictor of metastasis (Table1). The association between lymph node metastasis and overall survival after surgery was also showed by KaplanMeier curve (Figure1).

\section{Preoperative NLR, PLR and clinical parameters between PDCAs with and without $L N$ metastasis}

As showed in Table 2, platelet count and neutrophil count were not significantly different between those PDCA patients with nodal involvement and those without nodal involvement. However, both PLR and NLR were significantly higher in those patients with nodal involvement $(P<0.001$ and $P=0.006)$ (Table 2 and Figure 2). The ROC curves were further used to evaluate those variables. Figure 3 shows that the AUC of PLR $(0.656,95 \%$ CI $0.568-0.743)$ and NLR $(0.611,95 \%$ CI $0.521-0.701)$ were wider than neutrophils $(0.480,95 \%$ CI $0.387-0.573)$, platelet $(0.532,95 \%$ CI $0.440-0.624)$, and lymphocyte $(0.488,95 \%$ CI $0.396-0.580)$, which indicated that the ability of preoperative PLR and NLR values to differentiate $\mathrm{LN}$ metastasis is more powerful than individual indicators of lymphocyte, neutrophils, and platelet. 


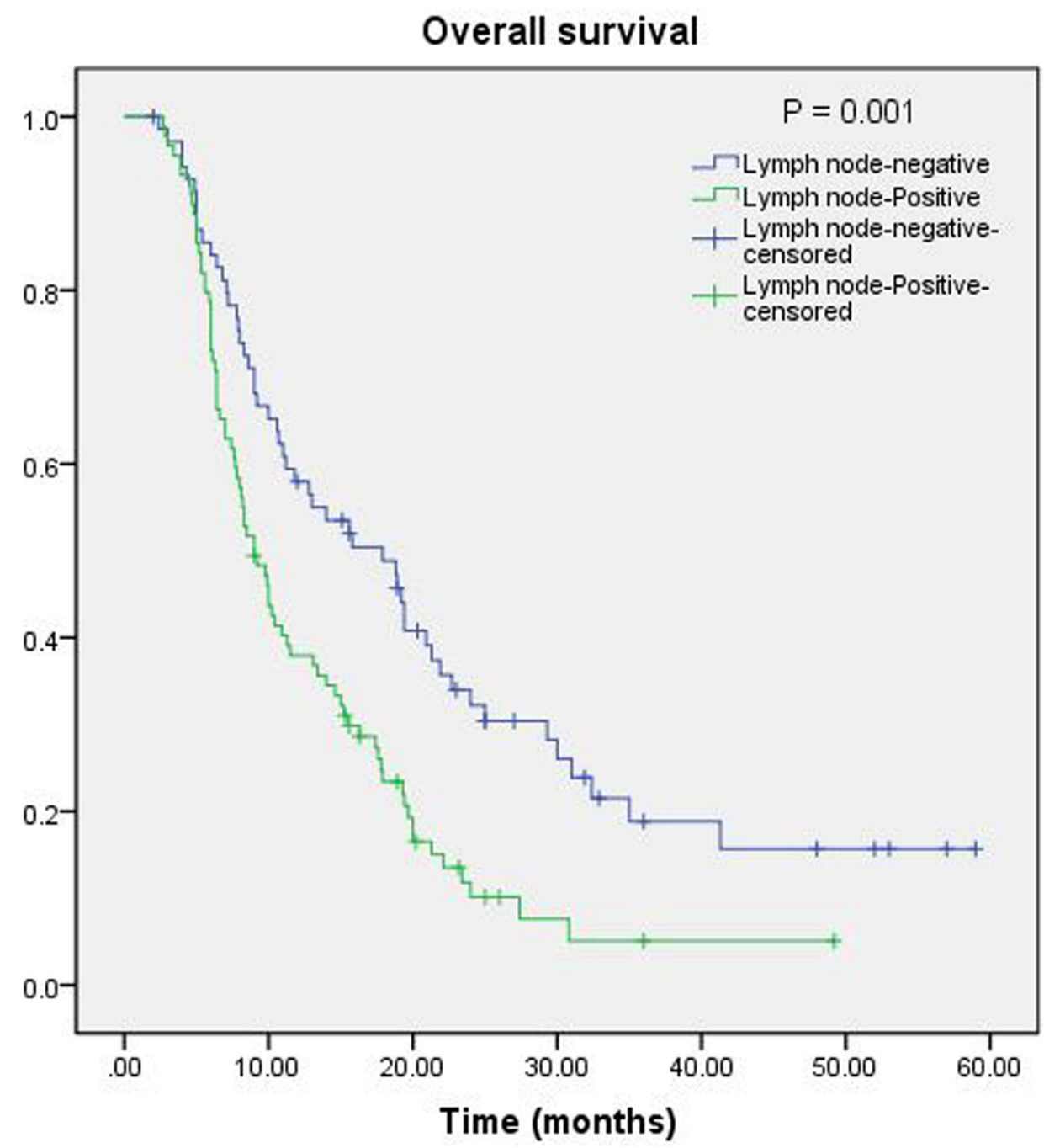

Figure 1: Kaplan-Meier curve for overall survival of patients with PDCA by lymph node-positive vs. lymph nodenegative; lymph node-positive is associated with poor survival $(P=0.001)$.
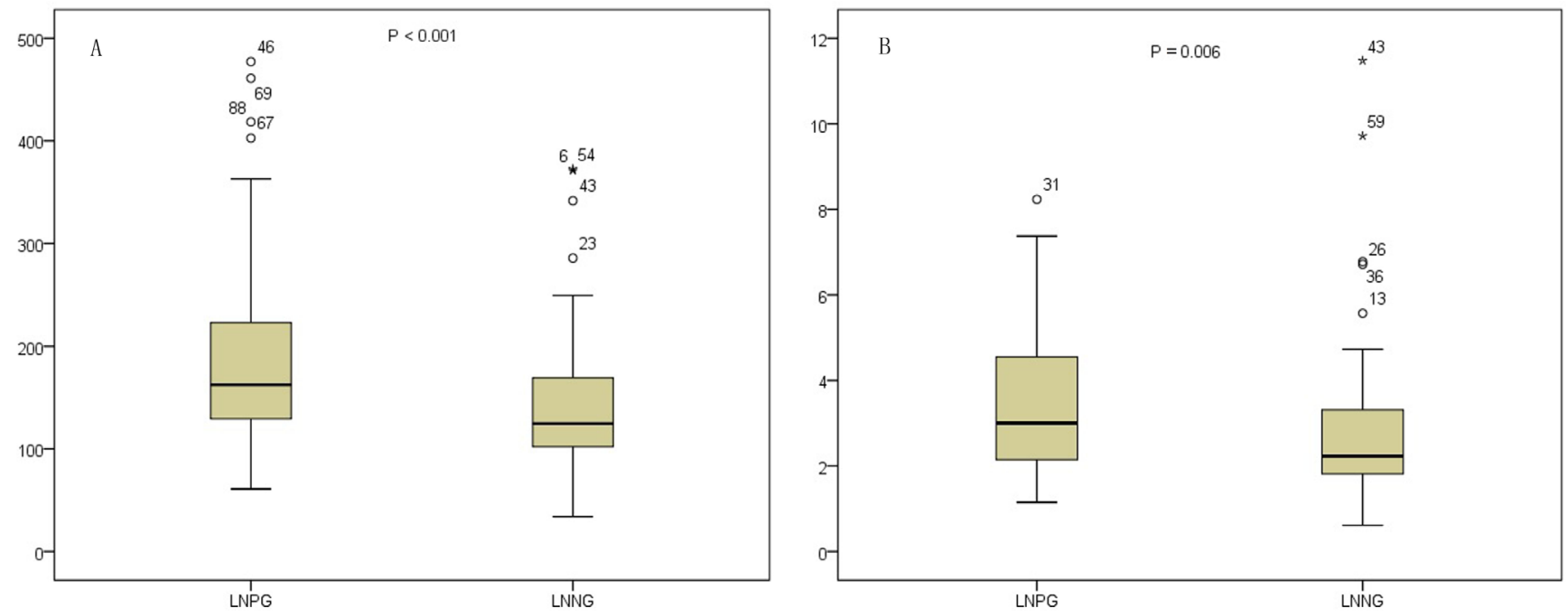

Figure 2: Distributions of PLR A. and NLR B. between LNNG and LNPG (LNNG, lymph node-negative group; LNPG, lymph node-positive group; NLR, neutrophil-to-lymphocyte ratio; PLR, platelet-to-lymphocyte ratio). 
Table 3: Univariate analysis of clinical characteristics according to nodal involvement

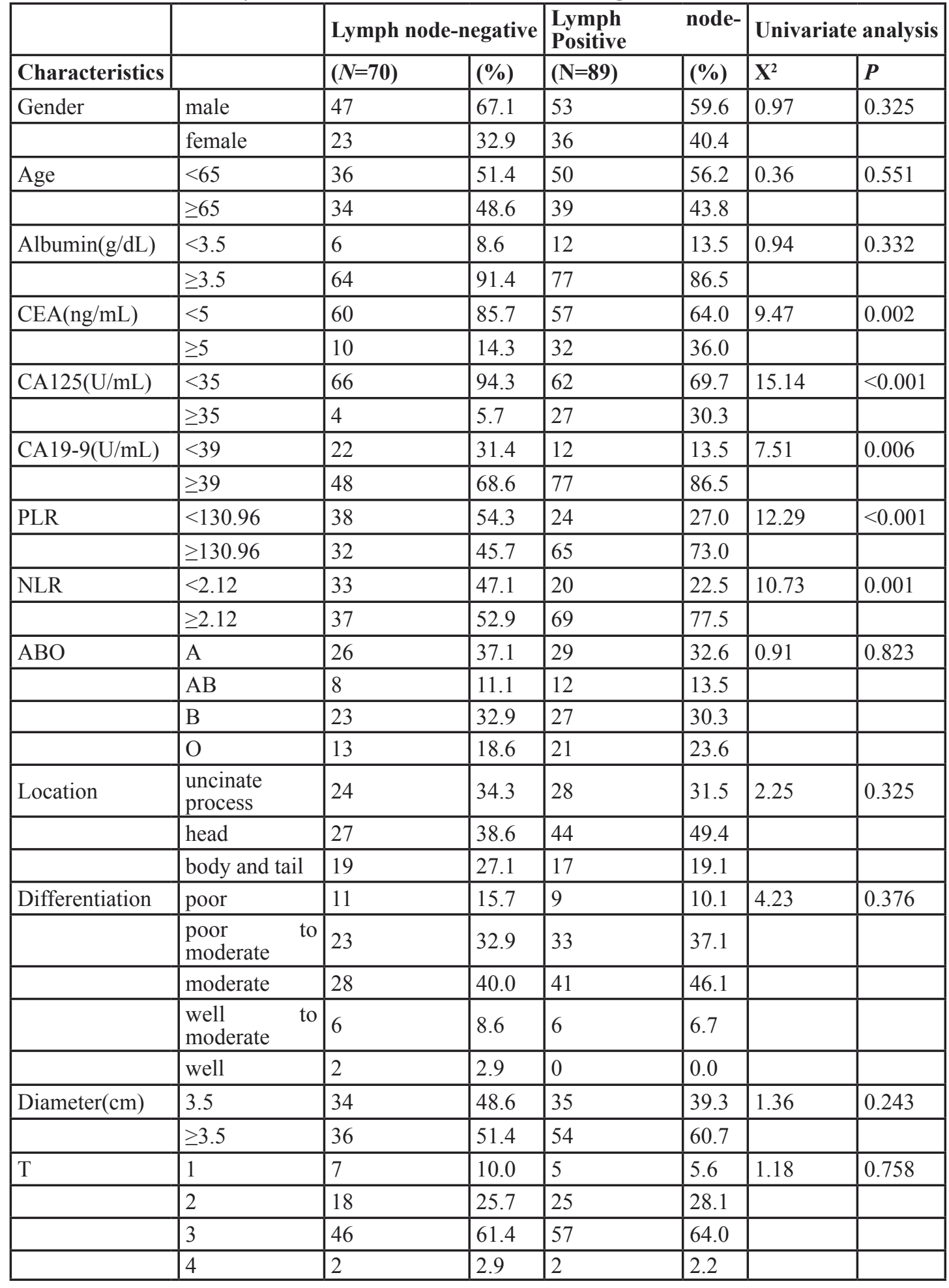

According to the ROC curve plotted above (Figure 3 ), the cutoff values of the PLR and NLR for LN metastasis were set to 130.96 and 2.12, respectively. On the basis of the cutoff value, the diagnostic sensitivity and specificity were 74.4 and $46.3 \%$, respectively, for PLR and 76.79 and $55.2 \%$, respectively, for NLR. Thus, we dichotomized the patients into groups of 'high PLR $(\geq 130.96)$ ' and 'low PLR ( < 130.96)' or 'high NLR $(\geq 2.12)$ ' and 'low NLR $(<2.12)^{\prime}$. Of 159 patients, the number of patients with high PLR and high NLR was 97 (61.0\%) and 106 (66.7\%), respectively. As showed in Table 1, the serum levels of CA19-9 and CA125 were statistically higher in the LN 
Table 4: Results of the clinicopathological parameters for PDCA with nodal involvement by multivariate logistic analyses

\begin{tabular}{|l|c|c|c|c|}
\hline \multicolumn{1}{|c|}{ Parameters } & & Hazard ratio & $\mathbf{9 5 \%}$ CI & $P$ value \\
\hline CEA(ng/mL) & $<\mathbf{5}$ & 1 & & \\
\hline & $\mathbf{2 5}$ & 1.714 & $0.682-4.303$ & 0.252 \\
\hline CA125(U/mL) & $<\mathbf{3 5}$ & 1 & & \\
\hline & $\geq \mathbf{3 5}$ & 6.348 & $2.056-19.594$ & 0.001 \\
\hline CA19-9(U/mL) & $<\mathbf{3 9}$ & 1 & & \\
\hline & $\geq \mathbf{3 9}$ & 2.738 & $1.151-6.515$ & 0.023 \\
\hline PLR & $<\mathbf{1 3 0 . 9 6}$ & 1 & & \\
\hline & $\geq \mathbf{1 3 0 . 9 6}$ & 1.852 & $0.832-4.123$ & 0.131 \\
\hline NLR & $<\mathbf{2 . 1 2}$ & 1 & & \\
\hline & $\geq \mathbf{2 . 1 2}$ & 2.588 & $1.246-5.376$ & 0.011 \\
\hline
\end{tabular}

positive group (both $P<0.001$ ) groups. With respect to the other quantitative clinical parameters including age, albumin, CEA, and tumor diameter, no significant difference was observed between the two groups.

\section{Univariate and multivariate analysis of LN metastases related factors}

Univariate analysis indicated that CEA $(\chi 2=9.47$, $P=0.002), \mathrm{CA} 125(\chi 2=15.14, P<0.001), \mathrm{CA} 19-9(\chi 2=$ $7.51, P=0.006), \operatorname{NLR}(\chi 2=10.73, \mathrm{P}=0.001)$, and PLR $(\chi 2=12.29, P<0.001)$ showed significant differences according to the nodal involvement (Table 3 ). There was no significant relationship between the LN-negative and LN positive groups with respect to gender, age, albumin, ABO blood type, tumor location, tumor differentiation, tumor diameter and $\mathrm{T}$ staging. Therefore, five variables examined in univariate analysis $(P<0.05)$ were selected as potential independent risk factors in multivariate analysis and the results showed (Table 4) that three of these differed significantly $(P<0.05)$. Finally, we identified that NLR (HR 2.588; 95\% CI 1.246-5.376; $P$ $=0.011)$, CA125 (HR 6.348; 95\% CI 2.056-19.594; $P=$ 0.001 ) and CA19-9 (HR 2.738; 95\% CI 1.151-6.515; $P$ $=0.023$ ) were independent predictive indicators of $\mathrm{LN}$ metastasis.

\section{DISCUSSION}

Our results show that $56.0 \%$ (89/159) PDCA patients had LN metastasis when diagnosed. Our analysis show indicated LN metastasis is a independently prognostic factor for overalls survival, which is agree with many previous studies and summed in a meta-analysis [6]. As a poor prognosis indicator, it is also a key preoperative factor for the selection of neoadjuvant therapy for PDCA patients [8]. Therefore, it is of great importance to find preoperative predictive indicators of $\mathrm{LN}$ metastasis in patients with PDCA.
Our data show that NLR and LN metastasis are closely related $(P=0.011)$. Inflammation has been reported to increase the risk of serious cancers, such as colorectal cancer, skin cancer, and lung cancer [29-33]. As the major part of WBCs, neutrophils play an important role in tumorigenesis and progression through secreting many types of cytokines, including IL-1, IL-8, granulocytemacrophage colony-stimulating factor (GM-CSF), and TNF- $\alpha$ [29]. It has been pointed out that neutrophils have a crucial role in tumor metastatic progression [22-24]. Zhang's study indicates that the abundance of circulating tumor-associated neutrophils in advanced cancer patients contributes to the circulating tumor cell survival and metastasis by suppressing peripheral leukocyte activation [25].

It is has been reported that through interaction with neutrophils, tumor cells could be brought to the endothelium, which is an essential step in LN metastases. Wculek and Malanchi clarify the role of mature neutrophils as mediators of metastatic initiation in breast cancer models [24]. Studies have indicated that tumor cells could activate and adhere to neutrophils directly through integrin $[34,35]$. Integrin $\alpha \mathrm{V} / \beta 3$, which is expressed by CTCs, could bind to surface receptors of neutrophils [36-39]. In addition, neutrophils could enhance indirect binding through paracrine of interleukin-8 and matrix metalloproteinase [40, 41]. Neutrophils also play a key role in adhesion of tumor cells to the lymphatic endothelium, which would bind to an endothelial cell if the endothelial is also sufficiently activated [42, 43]. Therefore, neutrophils might serve as mediators of the LN metastasis.

CA19-9 and CA125 are common serum markers for tumor, both are widely used in the clinic. CA19-9 is the most used serum marker in the diagnosis of PDCA [44-47], CA125 is mostly applied in ovarian cancer [48]. Many studies have proved the prognostic value of CA19-9 and CA125 in PDCA [44-47]. It was reported that CA125 levels specifically reflect the metastasis associated burden of pancreatic cancer in patients with advanced disease, 
as well as the presence of occult metastasis in patients with clinically localized tumors [46]. Our data indicate that both CA125 $(P=0.001)$ and CA19-9 $(P=0.023)$ are independent predictive indicator for LN metastasis, which is consisted with Zhou's study [47]. Therefore, CA125 and CA19-9 may be promising, noninvasive, LN metastasis associated biomarker for PDCA.

This study presents several limitations. Firstly, our study is hospital based on a single institution, not a population-based study. Such design might have introduced a selection bias because of differential referral patterns. However, such limitation was outweighed by its strength. We do not believe that we introduced an ascertaining bias for misdiagnosis, because all patients had both pathologically and clinically confirmed LN metastasis and PDCA. Secondly, the lost of information on some quantifiable factors, as well as the small size of patients, precluded us from estimating the magnitude of PDCA risk for LN metastasis associated with these factors. Although our study has a relatively small sample size, the incidence of LN metastasis is high in PDCA after operation, and given that this is a major focus of this study, the sample size is probably adequate.

In conclusion, the present study showed that NLR,

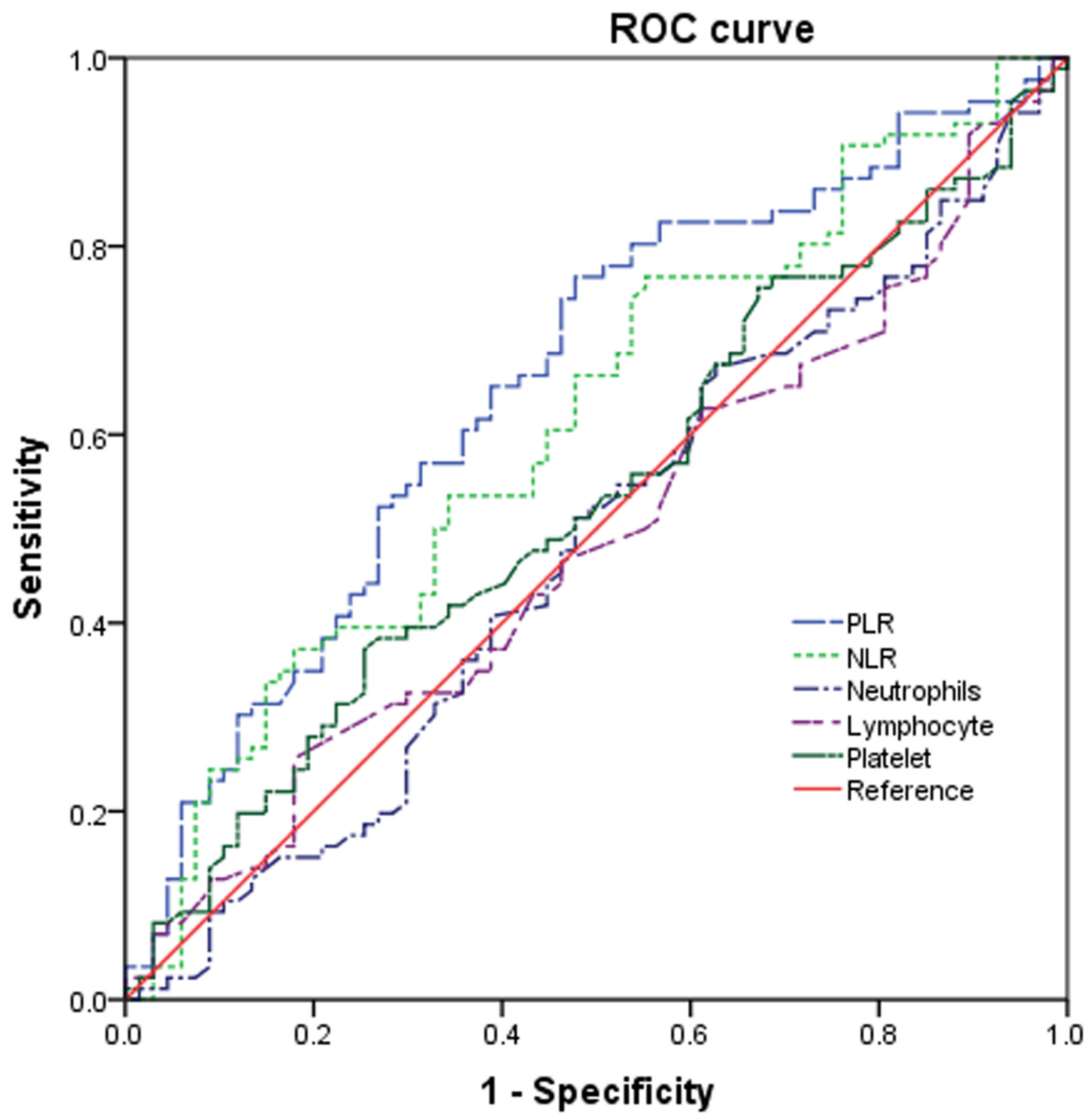

Figure 3: ROC curves for systemic inflammatory response markers in patients with PDCA according to lymph node metastasis (NLR, neutrophil-tolymphocyte ratio; PLR, platelet-to-lymphocyte ratio; ROC, receiver operating characteristic). 
CA125 and CA19-9 could be convenient, reliable and economical predictive tools to distinguish PDCA patients with LN metastasis between those without LN metastasis in the study, which are useful for further planning of selective neoadjuvant therapy or nodal dissection before surgery.

\section{MATERIALS AND METHODS}

\section{Ethical statement}

The study was approved by the Clinical Ethics Committee of Peking University Third Hospital. The patients' data were analyzed anonymously because written consent was not obtained from all participants.

\section{Study population and design}

All participants were enrolled from Peking University Third Hospital (Beijing, China) from February 2005 to December 2014. The patients who underwent a curative resection of primary PDCA and whose diagnoses were confirmed by pathological examination were involved in this study. Preoperative cytological examination was not regularly performed. Patients whose pre-operative examination showed celiac artery or superior mesenteric artery tumor invasion or distant metastasis (liver, lung and bone metastases) were not performed curative operation, no matter them have regional lymph node metastasis or not. However, four patients were found have liver metastasis during operation but not pre-operative examination. No other situation such as occult peritoneal disease which would explain high CA 125 during the included cases, as all of them was carefully checked. Eight PDAC patients who underwent neoadjuvant chemotherapy or chemoradiation therapy were excluded from the study. The NLR and PLR of the 159 PDAC patients were calculated in the database. All surgical specimens were evaluated pathologically to determine the extent of tumor differentiation, LN metastases, and surgical margins following surgery. The pathological stage of PDAC was determined according to the American Joint Committee on Cancer (AJCC)7th Edition [49]. According to the previously studies, the preoperative NLR was calculated as the neutrophil count divided by lymphocyte count [50], and the preoperative PLR was calculated as the platelet count divided by the lymphocyte count [51].

For the first 3 years following surgery, the patients were followed up at intervals of at most 3 months. These follow up visits consisted of a physical examination, laboratory examination including the measurement of tumor markers, and computed tomography (CT) or magnetic resonance imaging (MRI). In some cases, ultrasound or positron emission tomography-computed tomography (PET-CT) was also used. From the 3-year time point following surgery, the patients with no sign of metastasis or recurrence were monitored at 3- to 6-month intervals. The patients were followed up until death or December 31, 2015. The metastasis time was measured from the day of surgery to the date of the diagnosis of metastasis. The overall survival time was measured from the day of surgery to the date of death or the last followup.

\section{Statistical analysis}

The Mann-Whitney U-test and a box-plot were used to describe the normality of each continuous parameter's distribution. Quantitative results are reported in the form of the means \pm standard deviation. The ROC curve was used to estimate the performance of NLR and PLR. $\chi^{2}-$ test was used for univariate analysis of LN metastasis. The associations between clinical and histopathological parameters with OS and metastasis were analyzed using Kaplan-Meier curves and compared by the log-rank test. Univariate and multivariate Cox-regression analyses were performed to determine the effects of possible prognostic factors on metastasis after curative surgery. Hazard ratios (HRs) estimated from the Cox analysis were shown as relative risks with corresponding 95\% confidence intervals (CIs). The associations between the clinical and histopathological parameters with LN metastasis were evaluated by both univariate analysis and multivariate logistic regression analysis. On the basis of the univariate analysis, those variables with $P$ value less than 0.05 were included in the multivariate logistic regression analysis to confirm independent variables. The forward stepwise method was utilized to eliminate variables that did not show significant information. Hazard ratios (HRs) and 95\% confidence intervals (CIs) of each independent variable were calculated routinely. All analyses were carried out using the SPSS 22.0 statistical software (SPSS, IL, USA). $P<0.05$ was considered statistically significant.

\section{Institutional review board statement}

This study was approved by the Clinical Ethics Committee of Peking University Third Hospital.

\section{CONFLICTS OF INTEREST}

The authors declare no conflict of interest.

\section{FUNDING}

This study was supported by a grant from the Doctoral Fund of the Ministry Education of China (No. 20090001110096). 


\section{Author contributions}

Dr, Xiu Dianrong, and Tao lianyuan conceived and designed this study; Tao Lianyuan, who performed the HE; Tao Lianyuan, Xiu Dianrong, Yuan Chunhui, Ma Chaolai and Jian Bing performed the statistical analysis, interpretation of data; Ying Peng, Zhang Lingfu, Tao Ming, Li Gang performed the clinical data collection and samples collection; Tao Lianyuan and Xiu Dianrong wrote the manuscript. All authors read and approved the final manuscript.

\section{REFERENCES}

1. Hidalgo M. Pancreatic cancer. The New England journal of medicine. 2010; 362:1605-1617.

2. Zhang Q, Zeng L, Chen Y, Lian G, Qian C, Chen S, Li J and Huang K. Pancreatic Cancer Epidemiology, Detection, and Management. Gastroenterology research and practice. 2016; 2016:8962321.

3. Dimastromatteo J, Houghton JL, Lewis JS and Kelly KA. Challenges of Pancreatic Cancer. Cancer journal. 2015; 21:188-193.

4. Basturk O, Saka B, Balci S, Postlewait LM, Knight J, Goodman M, Kooby D, Sarmiento JM, El-Rayes B, Choi H, Bagci P, Krasinskas A, Quigley B, Reid MD, Akkas G, Maithel SK, et al. Substaging of Lymph Node Status in Resected Pancreatic Ductal Adenocarcinoma Has Strong Prognostic Correlations: Proposal for a Revised $\mathrm{N}$ Classification for TNM Staging. Annals of surgical oncology. 2015; 22 Suppl 3:S1187-1195.

5. Murakami Y, Uemura K, Sudo T, Hashimoto Y, Yuasa Y and Sueda T. Prognostic impact of para-aortic lymph node metastasis in pancreatic ductal adenocarcinoma. World journal of surgery. 2010; 34:1900-1907.

6. Paiella S, Sandini M, Gianotti L, Butturini G, Salvia R and Bassi C. The prognostic impact of para-aortic lymph node metastasis in pancreatic cancer: A systematic review and meta-analysis. European journal of surgical oncology. 2016; 42:616-624.

7. Li D and O'Reilly EM. Adjuvant and Neoadjuvant Therapy for Pancreatic Cancer. Surgical oncology clinics of North America. 2016; 25:311-326.

8. Roland CL, Yang AD, Katz MH, Chatterjee D, Wang H, Lin H, Vauthey JN, Pisters PW, Varadhachary GR, Wolff RA, Crane $\mathrm{CH}$, Lee JE and Fleming JB. Neoadjuvant therapy is associated with a reduced lymph node ratio in patients with potentially resectable pancreatic cancer. Annals of surgical oncology. 2015; 22:1168-1175.

9. Russo S, Ammori J, Eads J and Dorth J. The role of neoadjuvant therapy in pancreatic cancer: a review. Future oncology. 2016; 12:669-685.

10. Joosse SA, Gorges TM and Pantel K. Biology, detection, and clinical implications of circulating tumor cells. EMBO molecular medicine. 2015; 7:1-11.

11. Lan BY, Kwee SA and Wong LL. Positron emission tomography in hepatobiliary and pancreatic malignancies: a review. American journal of surgery. 2012; 204:232-241.

12. Lee YN, Moon JH, Kim HK, Choi HJ, Lee SH, Choi MH, Kim DC, Lee TH, Cha SW, Cho YD and Park SH. A triple approach for diagnostic assessment of endoscopic ultrasound-guided fine needle aspiration in pancreatic solid masses and lymph nodes. Digestive diseases and sciences. 2014; 59:2286-2293.

13. Prenzel KL, Holscher AH, Vallbohmer D, Drebber U, Gutschow CA, Monig SP and Stippel DL. Lymph node size and metastatic infiltration in adenocarcinoma of the pancreatic head. European journal of surgical oncology. 2010; 36:993-996.

14. Wang S, Zhang Q, Luo XF, Li J, He H, Yang F, Di Y, Jin C, Jiang XG, Shen S and Fu de L. Magnetic graphene-based nanotheranostic agent for dual-modality mapping guided photothermal therapy in regional lymph nodal metastasis of pancreatic cancer. Biomaterials. 2014; 35:9473-9483.

15. Tseng DS, van Santvoort HC, Fegrachi S, Besselink MG, Zuithoff NP, Borel Rinkes IH, van Leeuwen MS and Molenaar IQ. Diagnostic accuracy of CT in assessing extraregional lymphadenopathy in pancreatic and peri-ampullary cancer: a systematic review and meta-analysis. Surgical oncology. 2014; 23:229-235.

16. Moriya T, Kimura W, Hirai I, Takasu N and Mizutani M. Expression of MUC1 and MUC2 in ampullary cancer. International journal of surgical pathology. 2011; 19:441447.

17. Wang SC, Parekh JR, Porembka MR, Nathan $H$, D'Angelica MI, DeMatteo RP, Fong Y, Kingham TP, Jarnagin WR and Allen PJ. A Pilot Study Evaluating Serum MMP7 as a Preoperative Prognostic Marker for Pancreatic Ductal Adenocarcinoma Patients. Journal of gastrointestinal surgery. 2016.

18. Glen P, Jamieson NB, McMillan DC, Carter R, Imrie $\mathrm{CW}$ and McKay CJ. Evaluation of an inflammation-based prognostic score in patients with inoperable pancreatic cancer. Pancreatology. 2006; 6:450-453.

19. Jamieson NB, Glen P, McMillan DC, McKay CJ, Foulis $\mathrm{AK}$, Carter R and Imrie CW. Systemic inflammatory response predicts outcome in patients undergoing resection for ductal adenocarcinoma head of pancreas. British journal of cancer. 2005; 92:21-23.

20. Jamieson NB, Mohamed M, Oien KA, Foulis AK, Dickson EJ, Imrie CW, Carter CR, McKay CJ and McMillan DC. The relationship between tumor inflammatory cell infiltrate and outcome in patients with pancreatic ductal adenocarcinoma. Annals of surgical oncology. 2012; 19:3581-3590.

21. Neal CP, Mann CD, Garcea G, Briggs CD, Dennison AR and Berry DP. Preoperative systemic inflammation and infectious complications after resection of colorectal liver 
metastases. Archives of surgery. 2011; 146:471-478.

22. Kim J and Bae JS. Tumor-Associated Macrophages and Neutrophils in Tumor Microenvironment. Mediators of inflammation. 2016; 2016:6058147.

23. Liang $\mathrm{W}$ and Ferrara N. The Complex Role of Neutrophils in Tumor Angiogenesis and Metastasis. Cancer immunology research. 2016; 4:83-91.

24. Wculek SK and Malanchi I. Neutrophils support lung colonization of metastasis-initiating breast cancer cells. Nature. 2015; 528:413-417.

25. Zhang J, Qiao X, Shi H, Han X, Liu W, Tian X and Zeng X. Circulating tumor-associated neutrophils (cTAN) contribute to circulating tumor cell survival by suppressing peripheral leukocyte activation. Tumour biology. 2016; 37:5397-404.

26. Luo G, Guo M, Liu Z, Xiao Z, Jin K, Long J, Liu L, Liu $\mathrm{C}, \mathrm{Xu} \mathrm{J}, \mathrm{Ni} \mathrm{Q}$ and $\mathrm{Yu} \mathrm{X}$. Blood neutrophil-lymphocyte ratio predicts survival in patients with advanced pancreatic cancer treated with chemotherapy. Annals of surgical oncology. 2015; 22:670-676.

27. Teo M, Mohd Sharial MS, McDonnell F, Conlon KC, Ridgway PF and McDermott RS. Prognostic role of neutrophil-to-lymphocyte ratio in advanced pancreatic ductal adenocarcinoma: impact of baseline fluctuation and changes during chemotherapy. Tumori. 2013; 99:516-522.

28. Xue P, Kanai M, Mori Y, Nishimura T, Uza N, Kodama Y, Kawaguchi Y, Takaori K, Matsumoto S, Uemoto S and Chiba T. Neutrophil-to-lymphocyte ratio for predicting palliative chemotherapy outcomes in advanced pancreatic cancer patients. Cancer medicine. 2014; 3:406-415.

29. Grivennikov SI, Greten FR and Karin M. Immunity, inflammation, and cancer. Cell. 2010; 140:883-899.

30. Kazma R, Mefford JA, Cheng I, Plummer SJ, Levin AM, Rybicki BA, Casey G and Witte JS. Association of the innate immunity and inflammation pathway with advanced prostate cancer risk. PloS one. 2012; 7:e51680.

31. Lund AW, Medler TR, Leachman SA and Coussens LM. Lymphatic Vessels, Inflammation, and Immunity in Skin Cancer. Cancer discovery. 2016; 6:22-35.

32. Wang H, Taverna D, Stram DO, Fortini BK, Cheng I, Wilkens LR, Burnett T, Makar KW, Lindor NM, Hopper JL, Gallinger S, Baron JA, Haile R, Kolonel LN, Henderson BE, Newcomb PA, et al. Genetic variation in the inflammation and innate immunity pathways and colorectal cancer risk. Cancer epidemiology, biomarkers \& prevention. 2013; 22:2094-2101.

33. Young RP and Hopkins RJ. Genetic variation in innate immunity and inflammation pathways associated with lung cancer risk. Cancer. 2013; 119:1761.

34. Ten Kate M, Aalbers AG, Sluiter W, Hofland LJ, Sonneveld P, Jeekel J and Van Eijck CH. Polymorphonuclear leukocytes increase the adhesion of circulating tumor cells to microvascular endothelium. Anticancer research. 2007; 27:17-22.

35. Wu QD, Wang JH, Condron C, Bouchier-Hayes D and
Redmond HP. Human neutrophils facilitate tumor cell transendothelial migration. American journal of physiology Cell physiology. 2001; 280:C814-822.

36. Felding-Habermann B, O'Toole TE, Smith JW, Fransvea E, Ruggeri ZM, Ginsberg MH, Hughes PE, Pampori N, Shattil SJ, Saven A and Mueller BM. Integrin activation controls metastasis in human breast cancer. Proceedings of the National Academy of Sciences of the United States of America. 2001; 98:1853-1858.

37. Kikkawa H, Kaihou M, Horaguchi N, Uchida T, Imafuku H, Takiguchi A, Yamazaki Y, Koike C, Kuruto R, Kakiuchi T, Tsukada H, Takada Y, Matsuura N and Oku N. Role of integrin alpha(v)beta3 in the early phase of liver metastasis: PET and IVM analyses. Clinical \& experimental metastasis. 2002; 19:717-725.

38. Reinmuth N, Liu W, Ahmad SA, Fan F, Stoeltzing O, Parikh AA, Bucana CD, Gallick GE, Nickols MA, Westlin WF and Ellis LM. Alphavbeta3 integrin antagonist S247 decreases colon cancer metastasis and angiogenesis and improves survival in mice. Cancer research. 2003; 63:20792087.

39. Wu YJ, Muldoon LL, Gahramanov S, Kraemer DF, Marshall DJ and Neuwelt EA. Targeting alphaV-integrins decreased metastasis and increased survival in a nude rat breast cancer brain metastasis model. Journal of neurooncology. 2012; 110:27-36.

40. Huh SJ, Liang S, Sharma A, Dong C and Robertson GP. Transiently entrapped circulating tumor cells interact with neutrophils to facilitate lung metastasis development. Cancer research. 2010; 70:6071-6082.

41. Kerk N, Strozyk EA, Poppelmann B and Schneider SW. The mechanism of melanoma-associated thrombin activity and von Willebrand factor release from endothelial cells. The Journal of investigative dermatology. 2010; 130:22592268.

42. Fu C, Tong C, Wang M, Gao Y, Zhang Y, Lu S, Liang $\mathrm{S}$, Dong $\mathrm{C}$ and Long $\mathrm{M}$. Determining beta2-integrin and intercellular adhesion molecule 1 binding kinetics in tumor cell adhesion to leukocytes and endothelial cells by a gas-driven micropipette assay. The Journal of biological chemistry. 2011; 286:34777-34787.

43. Lee YS, Choi I, Ning Y, Kim NY, Khatchadourian V, Yang D, Chung HK, Choi D, LaBonte MJ, Ladner RD, Nagulapalli Venkata KC, Rosenberg DO, Petasis NA, Lenz HJ and Hong YK. Interleukin-8 and its receptor CXCR2 in the tumour microenvironment promote colon cancer growth, progression and metastasis. British journal of cancer. 2012; 106:1833-1841.

44. Chen Y, Gao SG, Chen JM, Wang GP, Wang ZF, Zhou B, Jin CH, Yang YT and Feng XS. Serum CA242, CA199, CA125, CEA, and TSGF are Biomarkers for the Efficacy and Prognosis of Cryoablation in Pancreatic Cancer Patients. Cell biochemistry and biophysics. 2015; 71:12871291.

45. Liu L, Xu H, Wang W, Wu C, Chen Y, Yang J, Cen P, 
Xu J, Liu C, Long J, Guha S, Fu D, Ni Q, Jatoi A, Chari $\mathrm{S}$, McCleary-Wheeler AL, et al. A preoperative serum signature of $\mathrm{CEA}+/ \mathrm{CA} 125+/ \mathrm{CA} 19-9>/=1000 \mathrm{U} / \mathrm{mL}$ indicates poor outcome to pancreatectomy for pancreatic cancer. International journal of cancer. 2015; 136:22162227.

46. Liu L, Xu HX, Wang WQ, Wu CT, Xiang JF, Liu C, Long J, Xu J, Fu de L, Ni QX, Houchen CW, Postier RG, Li $\mathrm{M}$ and $\mathrm{Yu}$ XJ. Serum CA125 is a novel predictive marker for pancreatic cancer metastasis and correlates with the metastasis-associated burden. Oncotarget. 2016; 7:59435956. doi: 10.18632/oncotarget.6819.

47. Zhou G, Niu L, Chiu D, He L and Xu K. Changes in the expression of serum markers CA242, CA199, CA125, CEA, TNF-alpha and TSGF after cryosurgery in pancreatic cancer patients. Biotechnology letters. 2012; 34:1235-1241.

48. Gubbels JA, Belisle J, Onda M, Rancourt C, Migneault M, Ho M, Bera TK, Connor J, Sathyanarayana BK, Lee B, Pastan I and Patankar MS. Mesothelin-MUC16 binding is a high affinity, $\mathrm{N}$-glycan dependent interaction that facilitates peritoneal metastasis of ovarian tumors. Molecular cancer. 2006; 5:50.
49. Edge SB and Compton CC. The American Joint Committee on Cancer: the 7th edition of the AJCC cancer staging manual and the future of TNM. Annals of surgical oncology. 2010; 17:1471-1474.

50. Wang DS, Luo HY, Qiu MZ, Wang ZQ, Zhang DS, Wang $\mathrm{FH}, \mathrm{Li} \mathrm{YH}$ and $\mathrm{Xu} \mathrm{RH}$. Comparison of the prognostic values of various inflammation based factors in patients with pancreatic cancer. Medical oncology. 2012; 29:30923100 .

51. Kinoshita A, Onoda H, Imai N, Iwaku A, Oishi M, Fushiya N, Koike K, Nishino H and Tajiri H. Comparison of the prognostic value of inflammation-based prognostic scores in patients with hepatocellular carcinoma. British journal of cancer. 2012; 107:988-993. 